\title{
LA TRANSLATIO DEL PODER AL SOBERANO. UNA TEORÍA JURÍDICO-POLÍTICA \\ EN EL SIGLO DE ORO
}

\author{
Juan Cruz Cruz \\ Universidad de Navarra \\ jcruz@unav.es
}

\section{NECESIDAD DEL PODER O AUTORIDAD}

I. Teorías medievales y tardomedievales sobre la autoridad coincidían en que ésta es un derecho natural, cuyo origen está en Dios. Santo Tomás lo expresa así: "Regia potestas potest considerari... uno quidem modo quantum ad ipsam potestatem: et sic est a Deo" (en el Commentarium in Epistolam ad Romanos, cap. XIII). Y después Francisco de Vitoria: "Si enim publicam potestatem ordinemus constitutam jure naturali, jus autem naturale Deum solum auctorem cognoscit: manifestum evadit potestatem publicam a Deo esse, nec hominum conditione, aut jure aliquo positivo contineri" (en Relectio De Potestate civili, n. 6). Lo mismo enseñaba Domingo de Soto ("Potestatem autem civilem Deus per legem naturalem, quae suae sempiternae participatio est, ordinavit. Hoc autem sic patet. Deus per naturam dedit rebus singulis facultatem se conservandi, suisque resistendi contrariis...”. Domingo de Soto, De iustitia et iure, IV, quaest. 4, art. I).

Esta autoridad no viene de Dios por un acto especial y gratuito, distinto del acto creador. La autoridad política no pertenece al orden sobrenatural. Luego viene de Dios por vía de la naturaleza, en tanto que Dios es creador de la naturaleza, y todo lo que está implicado en ella proviene de Dios. Al crear Dios al hombre le dotó de facultades, propiedades y derechos inherentes a su condición de persona, derechos naturales que sólo son divinos por su condición natural creada. La sociedad es un efecto de la naturaleza social del hombre; y una de sus propiedades originales y necesarias es la autoridad. De modo que ésta es de origen divino por ser un derecho natural.

Fue doctrina común que ningún hombre tiene en sí el poder de sujetar la voluntad libre de los demás con los vínculos de su propia potencia. Únicamente tiene esta potestad de Dios.

2. Ahora bien, este origen divino de la autoridad es, en un sentido muy preciso, inmediato. Tanto Vitoria y Soto, como Suárez y Molina, advertían que la 
"opinión común" entre los escolásticos era que la autoridad viene de Dios immediate (Francisco Suárez, De legibus, III, cap. 3, n. 2). Lo cual significa que no viene por un acto especial de Dios, que, aparte de la creación de la naturaleza, creara la autoridad y la concediera a la sociedad. Más bien, viene de Dios "tanquam autore naturae", es decir, la autoridad viene de Dios creadoramente presente en la naturaleza.

El término "immediate" está traído aquí contra los que pudieran negar la existencia del derecho natural y sostuvieran que todo derecho proviene de la voluntad humana: esta voluntad propia es la que crearía la autoridad o el derecho a gobernar. Por tanto, ese "immediate" significa que los cimientos de la vida humana y social son de orden natural, siendo la autoridad una exigencia de la naturaleza social humana o derecho natural. La voluntad humana sólo es causa próxima de la existencia de la sociedad política; pero una vez puesta su existencia, la autoridad brota necesariamente, como elemento inherente al ser político. Los individuos no tienen facultad para crear una sociedad política anárquica, sin autoridad. Ni el hombre puede cumplir con su misión personal de alcanzar la perfección humana fuera de la sociedad. El bien humano supone el bien común, una atmósfera social que sea propicia para fomentar su bienestar y perfección. Cuando una multitud dada tiende hacia ese bien común, tiene ya un fin o misión que realizar. Surge necesariamente ahí la facultad moral de exigir los medios para realizar ese fin, siendo la autoridad el principal medio de organizarse y gobernarse.

3. El término "immediate" indica, asimismo, que la autoridad no tiene un origen divino remoto. En sentido lato o remoto todo cuanto existe en el mundo proviene de Dios, que es causa universal de todas las cosas: y así hasta las instituciones que provienen directamente de la libre voluntad humana, son de origen divino en sentido remoto. En cambio, el derecho natural es de origen divino inmediato, porque emana de la intención de la naturaleza, que es la intención directa de Dios, y no de la voluntad humana. Como la autoridad es un derecho natural, se sigue también aquí que los rasgos esenciales de su naturaleza son independientes de la voluntad humana. El hombre no puede formar una sociedad anárquica: sólo la forma con la propiedad esencial de la autoridad.

La naturaleza, por sí sola, exige internamente la autoridad; mas para que ésta nazca como derecho real (para que la exigencia natural se traduzca en derecho o facultad moral de gobernar), es necesario el consentimiento ciudadano.

Se podría decir que la "inmediatez" de la autoridad es una "inmediatez mediada", a saber, porque viene "mediante" la naturaleza y, además "mediante" el consentimiento" de los ciudadanos. 
I. Apoyados en el principio del origen divino del poder, otros maestros medievales llegaron a defender que la autoridad en concreto viene también immediate de Dios a una persona. Unos enseñaban que todo poder desciende de Dios a la persona del Papa; éste retendría en sí la autoridad eclesiástica y concedería o trasladaría al príncipe el ejercicio de la autoridad civil. El rey, por tanto, quedaba enteramente sometido a la voluntad suprema del Papa. Otros, en cambio defendieron la teoría del derecho divino de los reyes, sobre la cual se erigieron las monarquías absolutistas. Por ejemplo Enrique IV en su lucha contra Gregorio VII y Felipe el Hermoso contra Bonifacio VII. Más tarde, en Inglaterra Jacobo I, oponiéndose al Parlamento inglés, la defendió en sus obras Basilicón Dorón y Ius liberae monarchiae. Fue aplicada también en Francia por los monarcas Luis XIV y XV. En síntesis, la teoría del derecho divino de los reyes argumenta que el principe recibe su potestad inmediatamente de Dios. Para este absolutismo político el príncipe queda libre de toda traba y limitación, pues su poder real pertenece a la categoría de lo sagrado (pueden verse varios testimonios antiguos en J. Leclercq, 1929, pp. 233 ss.), siendo la autoridad real a la vez civil y religiosa (Jacobus I, Jus liberae Monarchiae, p. 193). El rey es irresponsable ante los hombres: sólo responde ante Dios (véase Jacobus I, I6I9, t. I, p. 137). Nadie puede pedirle cuentas de su gestión.

2. Hubo una posición intermedia, y muy matizada, llamada regalista, defendida por Juan de París (I260-I306), el cual enseñaba que "el poder secular no es un poder inferior sometido a un poder más grande, del que procedería. Por eso el poder secular es más grande que el poder espiritual en un cierto ámbito, a saber, en el temporal; y no está sometido a aquel de ninguna manera, porque no ha nacido de él; pero tanto el uno como el otro han nacido inmediatamente del poder supremo, a saber, del poder divino... Los dos poderes son distintos, de tal suerte que el uno no depende del otro. Y si el espiritual viene inmediatamente de Dios, lo mismo ocurre con el secular. El Papa no posee los dos: el poder real no depende del Papa ni en su naturaleza ni en su ejecución. Dios ha querido que los poderes fuesen distintos" (De Regia potestate et papali, 1302; cfr. J. Leclercq, 1942, pp. I09-I32).

Como se puede apreciar, tanto la teoría del derecho divino de los reyes como la teoría que atribuye al Papa el poder temporal se apoyan en la convicción del carácter sagrado de la realeza.

Pero los citados maestros de la Escuela de Salamanca —-también Suárez y Molina-, no aceptaron esas teorías e hicieron una distinción neta entre la autoridad divina que recae en el Papa y la autoridad natural que recae en el pueblo y es trasladada o transferida al gobernante: la autoridad llega al príncipe 
mediante el consentimiento popular: el pueblo es el que transfiere o traslada la autoridad al príncipe.

\section{LA TRASLACIÓN DEL PODER DESDE EL PUEBLO AL PRÍNCIPE}

I. Por otra parte, manteniendo el principio de que la autoridad es un derecho divino que viene inmediatamente de Dios al pueblo, otros autores - como Occam, Marsilio de Padua y Nicolás de Cusa-, enseñaron que el pueblo no enajena o traslada en el principe un derecho natural, sino que solamente le hace una concesión del uso o ejercicio de la autoridad. El príncipe elegido por el pueblo sería simple delegado o ejecutor de la voluntad popular, la cual podía deponerle a su arbitrio.

Y, en fin, una vez eliminado todo elemento trascendente en la autoridad misma o en su ejercicio, desde la Ilustración se hizo muy común la teoría de que el sujeto nato de la autoridad está en la voluntad popular. Las personas que han sido designadas por la voluntad popular para el ejercicio del poder son meros delegados, que dependen del arbitrio del pueblo, único soberano. En sentido estricto la designación de la persona por la voluntad popular no implicaría una transferencia o traslación del poder.

2. Francisco de Vitoria, Domingo de Soto, Francisco Suárez y Luis de Molina - entre otros-, enseñaron que el sujeto natural o titular nato de la potestad política es la comunidad o cuerpo politico. El sujeto del derecho natural no puede ser una persona particular, porque en la esfera civil todos los hombres nacen iguales y ninguno en concreto es destinado por la naturaleza para superior de los demás (dice Suárez: "La razón natural no puede encontrar un motivo para hacer sujeto de esa potestad a una persona o a un conjunto de personas más que a otro conjunto. Luego por naturaleza sólo está inmediatamente en la comunidad": "Ex vi rationis naturalis nulla potest excogitari ratio cur haec potestas determinetur ad unam personam, vel ad certum numerum personarum infra totam comunitatem, magis quam ad alium; ergo ex vi naturalis concessionis solum est immediate in communitate"; Francisco Suárez, Defensio Fidei Catholicae, III, cap. 2, n. 7).

Pero como normalmente la comunidad no puede ejercer el poder por sí misma, debe determinar sus gobernantes que ejerzan la debida autoridad para conseguir el bien común. Esa determinación de la autoridad en concreto debe hacerse por consentimiento popular, ya que sólo el pueblo posee la autoridad o derecho de gobierno. Este consentimiento puede ser o bien adhesivo o bien electivo. El adhesivo ocurre cuando una persona se pone al frente de la comunidad con el consentimiento y adhesión de los demás: puede ser tácito o expreso, 
simultáneo o sucesivo. Pero los clásicos ven en el consentimiento electivo, o sea, en la elección popular, la forma normal y conveniente para designar la autoridad (Francisco Suárez, Defensio Fidei Catholicae, III, cap. 2, n. 19). Vitoria enseñaba que esta elección estaba determinada por el criterio de la mayoría ("Satis est ut major pars conveniat in unum ut jure fiat", Francisco de Vitoria, Relectio de Potestate civili, n. I4). Pues bien, este consentimiento popular no sólo designa a las personas, sino también transfiere o traslada la potestad o derecho de gobernar. Como el titular nato del poder político es el pueblo —el consentimiento popular, dice Vitoria- designa a la persona y le confiere el poder (Respublica... propiam autoritatem in regen transfert», Francisco de Vitoria, Relectio de Potestate civili, n. 8; tambien Roberto Berllarmino, Controvesiae, III, De laicis, cap. 6). Así queda constituido como soberano el príncipe elegido, pues tiene la autoridad requerida para gobernar.

Y aunque el pueblo nunca puede negar las atribuciones que son esenciales a toda autoridad, sí puede hacer la transferencia con las limitaciones que juzgue oportunas para el bien común —en cuanto al tiempo, a la extensión de las atribuciones y al modo de ejercerlas. Sin dicha transferencia de la autoridad se originaría una organización anárquica.

Por tanto, la forma jurídica de trasmitir la autoridad es, en los Maestros españoles, el consentimiento popular, el cual no sólo designa al sujeto, sino que le trasmite o transfiere el poder otorgándole así legitimidad. Este consentimiento, —modo jurídico de traslación o trasmisión-, fue interpretado por Suárez como pacto o contrato (Francisco Suárez, De legibus, III, cap. 2, n. 4; cap. 4, nn. 2-6; Defensio fidei Catholicae, III, cap. 2, nn. I2-20). Vitoria no habla de pactos, sino de consentimiento popular, el cual ha de ser normalmente electivo; y habla también de transferencia o traslación del poder, siguiendo la opinión común de aquella época.

Suárez habla incluso de un doble pacto: en primera instancia existe un pacto de asociación, que consiste en el consentimiento de las familias de vivir unidas para lograr el bien común; y existe, en segunda instancia, un pacto de sujeción, por el que las familias asociadas determinan la formación de una autoridad o gobierno y se comprometen a colaborar y obedecer sus mandatos. En el primero se obtiene la unidad de la multitud —en forma de comunidad—; en er segundo, la unidad de gobierno —en forma de sociedad estricta—, expresión de la anterior. Este contrato, según Suárez, no es preciso que sea solemne, ni expreso; basta que sea implícito, el cual existe desde el momento en que nace el consentimiento de los ciudadanos.

Ahora bien, la idea contractual figura en la obra de Suárez como un apéndice explicativo, por lo que probablemente posea un valor secundario en su sistema.

3. Una vez ocurrida la designación por el consentimiento popular, el verdadero soberano es la persona determinada y no ya el pueblo. Al pueblo toca obedecer 
sus mandatos y leyes, no siendo legítima la rebelión popular contra él. El soberano tiene derecho a servirse de la fuerza para asegurar el cumplimiento de la ley (Francisco Suárez, Defensio fidei Catholicae, III, cap. 3, n. 5). Pero, siendo la comunidad el titular nato, el cuerpo político de esa comunidad posee el dominio radical de ese poder. Cuando el príncipe se hace ilegítimo, porque se ha extralimitado en sus poderes o porque es tirano, el poder retorna a la comunidad. Y la comunidad tiene el derecho de destituir a la autoridad.

Hasta finales de la Edad Media existió la discusión de si es pueblo concede al Príncipe solamente el uso de la autoridad (concessio usus) o si también le transfiere la misma sustancia o autoridad (translatio substantiae). Hubo autores que se inclinaban por la primera solución, como se ha dicho: el príncipe tiene el uso de la autoridad, nada más.

Los maestros Vitoria, Soto, Suárez y Molina (Luis de Molina, De iustitia et iure, Tract. II, disput. 23 y 28) se inclinaron por la segunda: el pueblo transfiere la misma autoridad o derecho de gobernar y no sólo el uso. Sin embargo, reservaban al pueblo lo que denominaban dominio radical, potestad; el pueblo conserva la potestad en hábito, y no en acto.

En lo que se refiere a la traslación o transferencia, Vitoria contrapone, de un lado, la potestas a la autoritas; y afirma que la autoritas se transfiere, pero no así la potestas: "Quamvis enim a Respublica constituatur (creat namque Respublica regem) non potestatem sed propiam autoritatem in regem transfert» (Francisco de Vitoria, De Potestate civili, n. 8.). De otro lado, contrapone el dominium a la gubernatio, y dice que lo que se transfiere es la gubernatio: "Respublica non transtulit dominium suarum rerum in regem sed gubernationem" (Francisco de Vitoria, In STh I-II, q. IO5, art. 2). Pues bien, Vitoria afirma la transferencia de la autoridad (a la que denomina autoritas, gubernatio) pero no la transferencia de la potestas, que es el poder constituyente o dominium radical.

La potestas es un poder moral radical de obligar a los miembros de la comunidad a la colaboración del bien común. Y reside siempre en el cuerpo social, implicada en la naturaleza del todo social, donde los individuos están incorporados.

Esa potestas, que es inmanente siempre al cuerpo político, se ejerce por el órgano de la sociedad, que es el príncipe designado; y éste es la autoritas.

En el cuerpo social está siempre la potestas. En el príncipe está la autoritas, que es la misma potestas desempeñada por el príncipe designado por el todo social. La potestas está en la colectividad; y Vitoria podría haber dicho, con los modernos, que la soberanía radica siempre en el pueblo. Mas para Vitoria la potestas se ejerce por un órgano diferenciado, al cual necesariamente se incorpora; no es la autoridad un mero delegado, sino un órgano que tiene y desempeña la potestas. 
I. El consentimiento popular es necesario para la designación de la autoridad en concreto. Este principio es común a los autores españoles antes nombrados. En el aspecto civil los hombres son por naturaleza libres e iguales. Lo que significa que los individuos no nacen los unos destinados a la obediencia y los otros al mando: ningún hombre tiene de suyo el poder de dominar la voluntad libre de los demás.

Para que una persona particular se constituya en autoridad se requiere una designación. Esta designación proviene de la voluntad de los hombres, del consentimiento de la comunidad.

2. El consentimiento no sólo designa a la persona, sino que confiere o traslada el poder. No hay una donación inmediata y vertical del poder, sino horizontal, de la comunidad al soberano elegido.

Pero en el orden eclesiástico puede existir un consentimiento que solamente designa a la persona sin conferirle el poder — como ocurre con el Papa-, por lo que ese consentimiento no tiene luego dominio alguno sobre la autoridad, que es recibida verticalmente.

En el orden civil la voluntad del cuerpo político tiene dominio sobre el poder y, por eso, de ella depende la forma y las atribuciones del elegido, las cuales varían en el tiempo y en el espacio.

En síntesis:

a) Siendo la comunidad el sujeto natural del poder politico, el consentimiento de ese cuerpo político confiere el poder y lo transmite con diversas limitaciones. Si el cuerpo político no fuera el poseedor de tal derecho no tendría dominio sobre él, ni podría limitarlo.

b) Pero las formas concretas en que se realiza ese poder — formas de régimenno son de derecho natural: tienen un carácter positivo y dependen de la libre voluntad de la comunidad.

\section{BIBLIOGRAFÍA}

Jacobus I, I619: Opera Omnia, Londres.

Leclercq, J., I929: "Le théologique et le philosophique dans la controverse sur l'origine divine du pouvoir", Ephemerides Theologicae Lovanienses, VI, pp. 230 y ss.

—_, 1942: Jean de París et l'ecclésiologie du XIII siècle, París. 